\title{
DEMOCRACIA E REFORMAS: UMA ANÁLISE COMPARATIVA ENTRE O DISCURSO DE JOÃO GOULART NA CENTRAL DO BRASIL E O PENSAMENTO DE ALEXIS DE TOCQUEVILLE E JOHN STUART MILL
}

\author{
DEMOCRACY AND REFORMS: A COMPARATIVE ANALYSIS BETWEEN JOÃO \\ GOULART'S SPEECH IN CENTRAL DO BRASIL AND THE THOUGHT OF ALEXIS \\ DE TOCQUEVILLE AND JOHN STUART MILL
}

Pablo Pimentel"

\begin{abstract}
RESUMO
As reformas de base encampadas pelo presidente João Goulart (1919-1976) foram alvo de uma intensa disputa de sentidos e significados em um período de acirrada polarização política. Em plena Guerra Fria, essa luta pela imposição de narrativas teve como elemento fulcral o conceito de democracia. Opositores do então presidente denunciavam tais reformas como um atentado à ordem democrática - ou uma tentativa de impor o Socialismo -, enquanto Jango advogava que seu teor sinalizava para o aprofundamento da democracia no Brasil. Como exercício, este artigo propõe uma análise comparativa entre o aclamado discurso de João Goulart na Central do Brasil e o pensamento dos autores clássicos da democracia liberal, Alexis de Tocqueville e John Stuart Mill, para identificar aproximações e distanciamentos entre o pensamento político desses autores e o discurso do presidente que seria derrubado pelo golpe de 1964. Em específico, daremos ênfase à discussãa entre esses autores sobre os temas das reformas agrária e eleitoral presentes no discurso de Jango.
\end{abstract}

PALAVRAS-CHAVE: Alexis de Tocqueville. Democracia. João Goulart. John Stuart Mill.

\begin{abstract}
The basic reforms enacted by President João Goulart (1919-1976) were the target of an intense dispute of sense and meanings in a period of fierce political polarization. During the Cold War, this struggle for the imposition of narratives had the concept of democracy as a central element. Opponents of the then president denounced such reforms as an attack on democratic order - or an attempt to impose Socialism -, while Jango argued that its content signaled the deepening of democracy in Brazil. As an exercise, this article proposes a comparative analysis between the speech of João Goulart in Central do Brasil and the thought of the classic authors of liberal democracy Alexis de Tocqueville and John Stuart Mill to identify similarities and distances between the political thought of these authors and the speech of president who would be overthrown by the 1964 coup. In particular, we will emphasize the discussion between these authors on the themes of agrarian and electoral reforms present in Jango's speech.
\end{abstract}

KEYWORDS: Alexis de Tocqueville. Democracy., João Goulart. John Stuart Mill.

\footnotetext{
* Mestre em Ciência Política pela Universidade Federal do Paraná (UFPR). Pesquisador associado do Grupo de Pesquisa em Comunicação, Política e Tecnologia da Universidade Federal do Paraná (PONTE-UFPR). pablo.pimentel@ymail.com
} 


\section{INTRODUÇÃO}

Rio de Janeiro, treze de março de 1964. Pressionado por todos os lados, o presidente João Goulart realiza um grande comício na Central do Brasil com o objetivo de mobilizar as entidades de classe, sindicatos e trabalhadores em prol das chamadas reformas de base que seriam levadas à apreciação do Congresso Nacional. O discurso proferido por Jango naquela noite enfatizava a importância de reformas estruturantes para o país, em especial as reformas agrária e eleitoral. Setores conservadores do Congresso, das Forças Armadas, do empresariado e das classes médias reagem aos intentos do presidente e se manifestam contra o que consideravam uma tentativa de atropelo do Parlamento que poderia abrir as portas para uma "república sindicalista" ou uma "ameaça comunista". Dias depois, a Marcha da Família com Deus pela Liberdade (19 de março de 1964), a maior manifestação antijanguista, foi marcada por um forte viés anticomunista, com cartazes que apelavam para que o país não se transformasse numa nova Cuba. Esses episódios da vida política nacional precipitaram o golpe militar de 1964, sob a justificativa de que salvaria a democracia brasileira da "ameaça vermelha" (FICO, 2004).

A utilização do discurso da ameaça comunista para evitar reformas progressistas, curiosamente, já foi tema de uma assertiva do filósofo Karl Marx que, no contexto do golpe de Estado de Luis Bonaparte, na França, afirmou:

A sociedade é "salva" [ante o grito: Propriedade, família, religião, ordem] tantas vezes
quantas se contrai o círculo de seus dominadores e um interesse mais exclusivo se
impõe ao mais amplo. Toda reivindicacão ainda que da mais elementar reforma
financeira burguesa, do liberalismo mais corriqueiro, do republicanismo mais formal,
da democracia mais superficial, é simultaneamente castigada como um "atentado à
sociedade" e estigmatizada como "socialismo" (MARX, 1997, p. 31-32, grifo nosso).

Marx enfatiza a tentativa de veto a reformas que objetivam a ampliação mínima de uma democracia liberal a partir do estigma do socialismo e do atentado à ordem. Já João Goulart, em seu discurso na Central do Brasil, problematiza a oposição às suas reformas com a seguinte afirmação:

Chegou-se a proclamar [...] que esta concentração seria um ato atentatório ao regime
democrático como se no Brasil a reação ainda fosse dona da democracia, ou
proprietária das praças e ruas. Desgracada democracia a que tiver de ser defendida
por esses democratas. Democracia para eles não é o regime da liberdade de reunião
para o povo (GOULART, 2009, p. 80, grifo nosso).

Torna-se evidente aqui que o termo "democracia" foi alvo de uma disputa de narrativas. A partir dessa constatação, será que os elementos norteadores desse discurso de João Goulart podem ser encontrados em teóricos clássicos da democracia? Se sim, que aproximações ou diferenças podem ser percebidas?

Levando em conta essa problemática, este artigo propõe um diálogo entre o discurso de Jango na Central do Brasil e o pensamento de dois autores que estão no campo da democracia liberal, Alexis de Tocqueville e John Stuart Mill. Ênfase será dada à discussão entre esses autores sobre duas reformas relevantes no discurso de Jango, a reforma agrária e a reforma eleitoral. 
Cabe ressaltar que a proposta deste trabalho não tem por intenção avaliar ou criticar o discurso da Central do Brasil e seu respectivo contexto histórico a partir dos autores citados, o que poderia levar a análises anacrônicas, mas sim um exercício de análise comparativa para identificar aproximações e distanciamentos estritamente entre o discurso de João Goulart e o pensamento de Tocqueville e Stuart Mill. Em um primeiro momento, analisaremos fragmentos do discurso de Jango sobre a reforma agrária, tema mais abordado no discurso, e mobilizaremos o arcabouço teórico dos autores liberais aqui trazidos à discussão sobre a importância da questão da terra para a democracia. Da mesma forma, faremos esse exercício com respeito à reforma eleitoral e à importância do sufrágio e da representação política. Por fim, faremos uma reflexão sobre a discussão realizada.

\section{DA REFORMA AGRÁRIA}

Estaríamos, assim, brasileiros, ameaçando o regime se nos mostrássemos surdos aos reclamos da Nação, desta Nação e desses reclamos que, de Norte a Sul, de Leste a Oeste, levantam o seu grande clamor pelas reformas de base e de estrutura, sobretudo pela reforma agrária, que será o complemento da abolição do cativeiro para dezenas de milhões de brasileiros, que vegetam no interior, em revoltantes condições de miséria. [...] E, feito isto, os trabalhadores do campo já poderão, então, ver concretizada, embora em parte, a sua mais sentida e justa reivindicação, aquela que lhes dará um pedaço de terra para cultivar. Aí, então, o trabalhador e sua família irão trabalhar para si próprios, porque até aqui eles trabalharam para o dono da terra, a quem entregam, como aluguel, metade de sua produção (GOULART, 2009, p. 8084, grifo nosso).

Sem dúvida, a conclamação para a luta em prol da reforma agrária ocupa a maior parte do discurso de João Goulart. Nesse trecho, é ressaltada a importância de tal reforma, no sentido de complementar a "abolição do cativeiro", talvez se referindo às propostas rejeitadas de conciliar a libertação total dos escravizados com a reforma agrária no fim do século XIX, ou seja, no sentido de inaugurar, de fato, um regime de liberdade social no Brasil. Em outro trecho, Jango se utiliza de duas justificativas para legitimar sua proposta de reforma agrária para o país:

Como garantir o direito de propriedade autêntica quando, dos quinze milhões de brasileiros que trabalham a terra, no Brasil, apenas dois milhões e meio são proprietários? O que estamos pretendendo fazer no Brasil, pelo caminho da reforma agrária, não é diferente, pois, do que se fez em todos os países desenvolvidos do mundo. É uma etapa de progresso que precisamos conquistar e haveremos de conquistar (GOULART, 2009, p.85).

A garantia do direito à propriedade é evocada por João Goulart para a consecução da reforma, que ele ressalta ter sido uma etapa necessária para o progresso que os países desenvolvidos, à época, já tinham alcançado. Ainda nesse discurso, Jango anuncia a desapropriação de terras ao longo de rodovias, ferrovias e açudes - Decreto n. 53.700, de 13 de Março de 19641-, mas ressalta que apenas através de uma mudança constitucional o direito à terra seria de fato conquistado:

\footnotetext{
${ }_{1}^{1}$ Disponível em: https://www2.camara.leg.br/legin/fed/decret/1960-1969/decreto-53700-13-marco-1964-393661publicacaooriginal-1-pe.html. Acessado em: 25 nov. 2020.
} 
Não o podemos fazer, por enquanto, trabalhadores, como é de prática corrente em todos os países do mundo civilizado: pagar a desapropriação de terras abandonadas em títulos da dívida pública e a longo prazo. Reforma Agrária com pagamento prévio do latifúndio improdutivo, à vista e em dinheiro, não é reforma agrária. Reforma Agrária, como consagrado na Constituição, com pagamento prévio e a dinheiro é negócio agrário, que interessa apenas ao latifundiário, radicalmente oposto aos interesses do povo brasileiro. Sem reforma constitucional, trabalhadores, não há reforma agrária autêntica. Sem emendar a Constituição, que tem acima dela o povo, poderemos ter leis agrárias honestas e bem intencionadas, mas nenhuma delas capaz de modificações estruturais profundas (GOULART, 2009, p. 84).

Para Jango, era preciso, então, uma mudança na Constituição de 1946, que retirasse a obrigação do pagamento prévio para desapropriar terras que serviriam para a reforma agrária. Para o presidente, tal mudança constitucional só prejudicaria o que ele chama de "[...] uma minoria de insensíveis, que deseja manter o povo escravo e a Nação submetida a um miserável padrão de vida" (GOULART, 2009, p. 86). Além de atender a uma demanda social, Jango defende a reforma agrária como uma demanda progressista do mercado interno brasileiro, que precisaria produzir mais para sobreviver, ajudando, assim, a promover o crescimento industrial e uma melhor remuneração do trabalhador urbano (GOULART, 2009, p. 84). "Já sabemos que não é mais possível produzir sem reformar", acenava o presidente para a necessidade da reforma. Ainda em seu discurso, Jango afirma que a reforma agrária deveria começar em terras mais valorizadas, próximas aos grandes centros de consumo, o que facilitaria o escoamento da produção.

Uma melhor distribuição das terras como efeito e causa de uma democracia que garanta igualdade de condições é um importante tema da análise de Tocqueville, em A Democracia na América, de 1835. O sociólogo francês, no século XIX, ao viajar para os Estados Unidos da América, passa a descrever as condições que, segundo seu pensamento, fizeram com que esse país desenvolvesse instituições, leis e costumes que favoreciam o avanço da democracia. Em sua análise, Tocqueville (2005, p. 38) afirma que os imigrantes europeus que chegaram à América perceberam que para trabalhar a terra seria preciso apenas os "esforços constantes e interessados do proprietário." Para Tocqueville, logo se percebeu que a produção do campo não seria abundante para enriquecer, ao mesmo tempo, o proprietário e o colono. Sendo assim, "o terreno fragmentou-se então naturalmente em pequenos domínios que o proprietário cultivava por si só” (TOCQUEVILLE, 2005 [1835], p. 38).

Essa condição permitiria que não se encontrasse na Nova Inglaterra uma classe aristocrata, pois segundo o sociólogo francês, é na transmissão hereditária da grande propriedade fundiária que a aristocracia se legitima. Para Tocqueville (2005, p. 39), “uma nação pode apresentar imensas fortunas e grandes misérias; mas se essas fortunas não são territoriais, vemos em seu seio pobres e ricos, não há, na verdade, aristocracia." Porém, é através da chamada "lei de sucessões" que o autor considera estar o passo derradeiro para uma maior igualdade de condições. Tocqueville (2005, p. 57-58) afirma que "em virtude da lei das sucessões, a morte de cada proprietário acarreta uma revolução na propriedade; não apenas os bens mudam de dono, como mudam, por assim dizer, de natureza: eles se fracionam sem cessar em porções menores." Esse efeito viria pela garantia legal de uma partilha igual sobre a herança 
das terras e bens entre todos os filhos do proprietário. $\mathrm{O}$ autor ainda diagnostica dois efeitos dessa lei sobre a sociedade:

É esse o efeito direto e, de certa forma, material da lei. Nos países em que a legislação estabelece a igualdade das partilhas, os bens e, em particular, as fortunas territoriais devem pois ter uma tendência permanente a se atenuar. [...] Mas a lei da partilha igual não exerce sua influência apenas sobre a sorte dos bens; ela também age sobre a própria alma dos proprietários e chama as paixões deles em seu auxílio. Seus efeitos indiretos é que destroem rapidamente as grandes fortunas e, sobretudo, as grandes propriedades fundiárias (TOCQUEVILLE, 2005, p. 58).

Dessa forma, Tocqueville (2005, p. 59) conclui sua análise sobre a lei de sucessões afirmando que ela "procede por dois caminhos: agindo sobre a coisa, ela age sobre o homem; agindo sobre o homem, ela chega à coisa"; sendo assim, "ela consegue atacar profundamente a propriedade fundiária e fazer desaparecer com rapidez tanto as famílias como as fortunas." O autor ainda ressalta que tais mudanças estruturais sobre a divisão da terra poderiam causar inicialmente oposições:

Ela divide, partilha, dissemina os bens e o poder; acontece às vezes de as pessoas ficarem assustadas com a rapidez da sua marcha e, desesperando deter seu movimento, procurarem pelo menos criar diante dela dificuldades e obstáculos, pretenderem contrabalançar sua ação mediante esforços contrários. Cuidados inúteis! Ela esmaga ou faz voar em pedaços tudo o que encontra em sua passagem, ergue-se e toma incessantemente a cair no chão, até que este não apresente à vista mais que uma poeira movediça e impalpável, sobre a qual se assenta a democracia (TOCQUEVILLE, 2005, p. 57).

Em sua visão, o viés inexorável e irresistível da democracia no mundo impediria que retrocessos pudessem acontecer e, sendo assim, tudo caminharia para a ampliação da igualdade de condições cuja partilha mais igualitária da terra seria parte integrante e fundamental desse processo.

O filósofo e economista inglês John Stuart Mill também se envolveu na discussão sobre a distribuição da terra, inclusive se engajando na luta pela reforma das leis de apropriação das terras na Inglaterra e na Irlanda, ajudando a escrever o programa do Land Tenure Reform Association. Segundo Ekelund Jr. e Tollison (1976, p. 213), "a preocupação de Mill com justiça distributiva de longo prazo era a característica distintiva do seu pensamento social." Laura Valladão de Mattos (2008) afirma que Stuart Mill pensava que era importante melhorar a igualdade de oportunidade para tornar o sistema mais justo, eficiente e trazer progresso individual. Assim como Tocqueville, Stuart Mill também via nas leis sobre a herança uma forma de melhorar a distribuição da propriedade. "A possibilidade de alguns indivíduos receberem de herança enormes fortunas derivadas do trabalho e abstinência de outrem seria incompatível com os argumentos usualmente utilizados na defesa da propriedade privada" (MATTOS, 2008). Para mudar esse panorama, a proposta do pensador inglês limitaria o quanto cada herdeiro poderia receber de herança (MILL, 1965, p. 225).

Além de considerar uma melhor distribuição da propriedade como relevante para uma sociedade com igualdade de oportunidades, Stuart Mill também acreditava que uma organização e distribuição da terra que pudesse atender as maiorias ajudariam na eficiência do sistema econômico. O autor afirma que 
"completo tem sido o fracasso da economia agrícola inglesa, se nós olharmos [...] para o verdadeiro teste - a condição da massa da população" (MILL, 1967, p. 681). Segundo o autor, a legitimidade e justiça da apropriação da terra estavam vinculadas à ideia de que ela conduziria a uma utilização mais produtiva da terra (MILL, 1965, p. 228). Para Stuart Mill (1965, p. 183), "nenhum melhoramento opera mais diretamente sobre a produtividade do trabalho do que aqueles na posse das fazendas e nas leis relacionadas à propriedade de terras." Entre suas propostas estavam tornar as propriedades de terras mais baratas, facilitar a sua transferência e tornar os contratos de locação mais vantajosos para aqueles que a cultivam (MATTOS, 2008). Além dessas propostas, o pensador também propôs que o Estado comprasse terras e as arrendasse para capitalistas, pequenos proprietários e cooperativas rurais (MILL, 1967, p. 693). Dessas três categorias, Stuart Mill considera que a destinação ideal dessas terras seria às cooperativas.

O autor afirma que "combinações tais como as associações entre trabalhadores [...] são os mais poderosos meios de efetuar a emancipação social dos trabalhadores por meio de suas próprias qualidades morais" (MILL, 1965, p. 904). Porém, ao se debruçar sobre o caso da Irlanda, ele afirma que a divisão da terra entre pequenos proprietários "seria a melhor forma de superar o atraso e pobreza vigentes" (MILL, 1965, p. 324). Com respeito à Inglaterra, o autor afirma que a pequena propriedade era uma modalidade superior a uma em que trabalhadores assalariados estariam submetidos a um capitalista, pois teria melhor efeito sobre "o caráter, sobre a industriosidade, empenho, inteligência, prudência, frugalidade dos homens e, em especial, sobre o controle populacional” (MILL., 1965, p. 295-296 e 767). Schwartz (1968, p. 296) explica que "apesar da importância que Mill lhe concedia, o sistema de propriedade camponesa acabou sendo para ele um remédio temporário ou local que seria substituído com o tempo pela associação ou pela cooperação." Concluindo o pensamento de Stuart Mill sobre sua forma ideal de distribuição da terra através de cooperativas, Mattos (2008) explica:

Mill via no surgimento das cooperativas uma alternativa muito interessante, pois estas
permitiam aproveitar a eficiência da produção em larga escala, dividir os seus frutos
de forma mais equitativa e não envolviam as relações espúrias de dependência e
servilismo observadas sob o cultivo capitalista. Por estas razões o autor considerava
que, na Inglaterra, a proliferação de cooperativas no campo seria a forma de cultivo
mais favorável à promoção do progresso.

Conclui-se, portanto, que existia uma preocupação, entre os autores estudados, com os conceitos de igualdade de condições ou oportunidades, e uma reforma agrária que garantisse o direito de propriedade ao maior número de cidadãos possível teria um caráter de extrema relevância para a efetivação dessa igualdade. Além disso, a possibilidade de um maior número de pessoas ter acesso à terra garantiria a emancipação social e, também, aumentaria as potencialidades do sistema econômico. Todos esses elementos estão contemplados no discurso da Central do Brasil como anseios de um Brasil mais livre, justo e igualitário. 


\title{
DA REFORMA ELEITORAL
}

\begin{abstract}
O povo quer que se amplie a democracia, quer que se ponha fim aos privilégios de uma minoria; quer que a propriedade da terra seja acessível a todos; que a todos seja facilitado participar da vida política do país, através do voto, podendo votar e ser votado; que se impeça a intervenção do poder econômico nos pleitos eleitorais e que seja assegurada à representacão de todas as correntes políticas, sem quaisquer discriminações, ideológicas ou religiosas (GOULART, 2009, p. 82, grifo nosso).
\end{abstract}

Em seu proeminente discurso, João Goulart também faz uma defesa enfática de uma reforma eleitoral que amplie o direito ao sufrágio e o direito à elegibilidade, o que, consequentemente, ampliaria a base da democracia brasileira. A sua preocupação em assegurar a representação política de todas as correntes também se insere, em seu discurso, no contexto da democratização dos direitos políticos e do combate ao domínio das elites econômicas e aos privilégios de minorias. Goulart (2009, p. 80) ainda afirma que "não há ameaça mais séria para a democracia do que tentar estrangular a voz do povo, dos seus legítimos líderes populares, fazendo calar as suas reivindicações," Em outro trecho, o ex-presidente descreve um pouco mais sua proposta:

Refiro-me à reforma eleitoral, à reforma ampla que permita a todos os brasileiros maiores de 18 anos ajudar a decidir dos seus destinos, que permita a todos os brasileiros que lutam pelo engrandecimento do país a influir nos destinos gloriosos do Brasil. Nesta reforma, pugnamos pelo princípio democrático, princípio democrático fundamental, de que todo alistável deve ser também elegível (GOULART, 2009, p. 88).

Entre os grupos de cidadãos que estavam alijados do processo eleitoral pela constituição de 1946 - e que, segundo a reforma eleitoral proposta por Jango, passariam a obter o direito à participação e representação - estavam principalmente os analfabetos e os militares de baixa patente.

Célebre por sua defesa de um governo mais representativo, Stuart Mill, cerca de um século antes de João Goulart, já escrevia sobre a importância da ampliação do sufrágio e da representação, principalmente na obra Consideraçôes sobre o Governo Representativo. O economista inglês afirmava que "nenhum sistema de sufrágio que excluir pessoas ou classes, ou seja, em que privilégio eleitoral não esteja à disposição de todas as pessoas maiores de idade que o desejarem, poderá ser permanentemente satisfatório" (MILL, 1981, p. 89). Stuart Mill (1981, p. 92) ainda reafirma que "é absolutamente necessário, dentro da concepção estendida e elevada do bom governo, que o sufrágio seja o mais largamente distribuído.” Apesar de sua defesa da ampliação do direito ao sufrágio, inclusive às mulheres em pleno século XIX, Stuart Mill (1981, p. 89 e 91) faz ressalvas quanto ao direito de alguns grupos ao voto, como analfabetos e pessoas que receberiam auxílio financeiro do governo. Para o autor, apesar do impedimento desses grupos ao voto ser um mal em si mesmo, não haveria conflito com seu ideal de ampliação do direito ao sufrágio. No caso dos analfabetos, Stuart Mill (1981, p. 89-90) afirma que o Estado deveria garantir os conhecimentos elementares de forma gratuita a todos ou, então, por um valor que os mais pobres pudessem arcar para então participar dos pleitos eleitorais. Porém, afirma o autor, se 
não for esse o caso e o Estado cometer essa injustiça de não prover tais conhecimentos, ainda assim o direito à educação universal deveria preceder o direito ao sufrágio universal.

Stuart Mill (1981, p. 32) reflete, ainda, que as classes trabalhadoras, em seu tempo, não tinham alcançado o direito de participar diretamente do governo e se encontravam num estado de completa exclusão política. Ao constatar essa realidade, ele propõe a seguinte elucubração:

\begin{abstract}
Contudo, o Parlamento, ou qualquer um de seus membros, alguma vez já examinou uma questão qualquer com os olhos do trabalhador? Quando um assunto de interesse para os ditos trabalhadores é levantado, ele é examinado de um ponto de vista diferente daquele dos patrões? Não digo que a visão dos trabalhadores nestas questões é geralmente mais perto da verdade do que as outras: mas em alguns casos é tão perto quanto; e em todos os casos ela deve ser respeitosamente ouvida, ao invés de ser, como tem sido, não apenas afastada, mas também ignorada. [...] Não é, contudo, necessário afirmar tudo isto para apoiar o direito de todos a participarem do poder soberano. Não precisamos supor que quando o poder reside exclusivamente em uma classe, esta classe deverá consciente e deliberadamente sacrificar em favor de si mesma as outras classes; basta saber que na ausência de seus defensores naturais os interesses dos excluídos estarão sempre em perigo de serem negligenciados; e que, quando forem considerados, o serão com olhos bem diferentes dos das pessoas a quem concernem diretamente (MILL, 1981, p. 32).
\end{abstract}

Ao analisar essa realidade, Stuart Mill (1981, p. 32) afirma que "cada um é o melhor guardião de seus próprios direitos e interesses." Nesse sentido, seria de extrema importância que houvesse uma representação equitativa entre as classes no Parlamento. Para Stuart Mill (1981, p. 31), "um governo totalmente popular é a única política que pode ter alguma pretensão de possuir essa característica, [...] a excelência de uma constituição política. [...] Ele é o mais favorável a uma boa direção dos negócios e a uma elevação e aprimoramento do caráter nacional." O autor também afirma que "a forma ideal de governo é aquela em que a soberania [...] pertence à massa reunida da comunidade; aquela em que todo o cidadão não apenas tem uma voz no exercício do poder supremo, mas também é chamado [...] a tomar parte ativa no governo pelo exercício de alguma função pública, local ou geral” (MILL, 1981, p. 31). Para concluir esse breve panorama do pensamento de Stuart Mill sobre a importância da ampliação da representação e do sufrágio, o autor resume seu pensamento:

Uma democracia como esta que acabamos de esboçar, na qual todos seriam representados, não apenas a maioria — onde os interesses, as opiniões, os níveis de inteligência que estão em minoria, seriam ouvidos apesar de tudo, e teriam uma chance de obter, pelo peso de sua reputação, e pela potência de seus argumentos, uma influência superior à sua força numérica - esta democracia, onde existiria a igualdade, a imparcialidade, o governo de todos por todos, a única democracia verdadeira, estaria livre dos grandes males das democracias falsas, hoje em grande número, e que servem de base para a ideia corrente que se faz de democracia (MILL, 1981, p. 87).

No pensamento de Tocqueville, em sua análise sobre as instituições democráticas estadunidenses, há uma advertência sobre os perigos do que ele chama de "tirania das maiorias". O autor francês considera "ímpia e detestável a máxima de que, em matéria de governo, a maioria do povo tem o direito de fazer tudo; apesar disso [situava] na vontade da maioria à origem de todos os poderes" (TOCQUEVILLE, 2005, p. 294). Ou seja, apesar de assegurar que a legitimidade da democracia está na 
vontade da maioria, isso não quer dizer que ela pudesse tudo, passando assim por cima das minorias. Para Tocqueville (2005, p. 294), o limite à tirania da maioria seria imposto pela justiça.

Ainda sobre a representação e o direito popular de participação nos EUA do século XIX, afirma Tocqueville (2005, p. 67-68):

\begin{abstract}
Ora o povo em corpo faz as leis, como em Atenas; ora deputados, que o voto universal criou, o representam e agem em seu nome sob sua vigilância quase imediata. [...] O povo participa da composição das leis pela escolha dos legisladores, da sua aplicação pela eleição dos agentes do poder executivo; podemos dizer que governa por si mesmo, a tal ponto a importância deixada à administração é fraca e restrita, a tal ponto ela é marcada por sua origem popular e obedece ao poder de que emana. $\mathrm{O}$ povo reina sobre o mundo político americano como Deus sobre o universo. Ele é a causa e o fim de todas as coisas. Tudo provém dele e tudo nele se absorve.
\end{abstract}

A importância que Tocqueville confere à participação popular na elaboração das leis e na escolha dos seus representantes demonstra a relevância que esses quesitos tinham em relação à constatação anterior do autor sobre a ampliação da democracia através de um irresistível avanço da igualdade de condições. Sobre esse avanço, o autor acrescenta que se trata de um processo sem volta; um processo de constante crescimento democrático, como fica evidenciado neste próximo trecho, ao dissertar sobre a diminuição das barreiras para o exercício do voto:

\footnotetext{
Quando um povo começa a tocar no censo eleitoral, pode-se prever que chegará, num prazo mais ou menos longo, a fazê-lo desaparecer completamente. Essa é uma das regras mais invariáveis que regem as sociedades. À medida que se recua o limite dos direitos eleitorais, sente-se a necessidade de recuá-lo ainda mais; porque, depois de cada nova concessão, as forças da democracia aumentam e suas exigências crescem com seu novo poder. A ambição dos que são deixados abaixo do censo inflama-se proporcionalmente ao grande número dos que se acham acima. A exceção se torna enfim a regra; as concessões sucedem-se sem parar e só se para quando se chega ao sufrágio universal (TOCQUEVILLE, 2005, p. 67).
}

Essas passagens dos autores liberais aqui abordados demonstram - apesar de algumas diferenças como o direito de voto aos analfabetos - a importância da participação, da representação política, da ampliação do direito ao sufrágio e da soberania popular para a efetivação de uma real democracia, direitos defendidos no discurso de João Goulart como forma de garantir a democratização política e social do país.

\title{
CONSIDERAÇÕES FINAIS
}

Ao longo deste trabalho, mobilizamos o pensamento de Alexis de Tocqueville e John Stuart Mill, autores clássicos do campo liberal no século XIX, para evidenciar conceitos importantes sobre a ampliação da democracia. Como discutimos aqui, entre os conceitos fundamentais para a democratização está a igualdade de condições e de oportunidades. Para a consecução desses objetivos, os autores defendiam uma melhor distribuição da terra a partir do inevitável enfrentamento ao sistema de grandes propriedades fundiárias e das grandes fortunas. Propunha-se o combate à pobreza e à miséria 
promovendo a emancipação e o progresso social, a importância do direito ao voto e sua ampliação para que se garantisse o exercício da voz de todas as classes e correntes políticas e que se aumentasse a representação política nos governos fazendo com que as minorias pudessem defender seus direitos e interesses. Essas proposições dialogam plenamente como o discurso e as propostas proferidas por João Goulart na Central do Brasil em 1964. Discurso e propostas, como as reformas agrária e eleitoral, que foram acusadas de ser uma estratégia de atentar contra a democracia por setores conservadores da sociedade brasileira de meados do século XX.

Ao defender as propostas e ações de seu governo, João Goulart (2009, p. 80) afirma que o que seus detratores queriam era "uma democracia de um povo emudecido, de um povo abafado nos seus anseios, de um povo abafado nas suas reivindicações". Ele ainda exclama que "[...] a democracia que eles [seus opositores] pretendem é a democracia dos privilégios, a democracia da intolerância e do ódio" (GOULART, 2009, p. 80). Nas palavras de Stuart Mill (1981, p. 87), uma democracia falsa que "não será jamais a melhor forma de governo [...] a não ser que possa ser organizada de maneira a não permitir que nenhuma classe [...] possa reduzir todo o resto à insignificância política, e dirigir o curso da legislação e da administração segundo seus interesses exclusivos de classe." Concluímos, então, que, ressalvadas as diferenças de contexto histórico, político e social, o discurso de João Goulart e suas propostas reformistas se aproximam dos elementos constituintes da ampliação da democracia liberal pensada pelos autores aqui estudados e são preocupações relevantes para a constante democratização da cidadania, tarefa ainda inconclusa na sociedade brasileira do século XXI.

\section{REFERÊNCIAS}

EKELUND JR, R. B.; TOLLISON, R. D. The new political economy of J. S. Mill: the means to social justice. The Canadian Journal of Economics, v. 9, n. 2, p. 213-231, 1976.

FICO, C. Além do Golpe: versões e controvérsias sobre 1964 e a Ditadura Militar. Rio de Janeiro: Record, 2004.

GOULART, J. Discursos selecionados do presidente João Goulart. Org. de Wanielle Brito Marcelino. Brasília: Funag, 2009.

MARX, K. O 18 Brúmario e Cartas a Kugelman. Rio de Janeiro: Paz e Terra, 1997.

MATTOS, L. V. Rumo a uma sociedade melhor: uma análise da agenda de reformas econômicas de J. S. Mill. Estudos Econômicos, São Paulo, v. 38, n. 2, p. 293-317, 2008. Disponível em: http:/ /www.scielo.br/scielo.php?script=sci_arttext\&pid=S0101-

$41612008000200004 \& \operatorname{lng}=$ en\&nrm=iso. Acessado em: 27 jul. 2020.

MILL, J. Considerações sobre o Governo Representativo. Brasília: Ed. da UNB, 1981.

MILL, J. S. Leslie on the land question. In: ROBSON, J. M. (ed.) Essays on Economics and Society, 18501879, CW V. Toronto: University of Toronto Press, 1967. 
MILL, J. S. Principles of political economy with some of their applications to social philosophy. In: ROBSON, J. M. (ed.) Essays on Economics and Society, 1850-1879, CW II e III, Toronto: University of Toronto Press, 1965.

SCHWARTZ, P. La Nueva Economia Politica de John Stuart Mill. Madrid: Tecnos, 1968.

TOCQUEVIlle, A. A democracia na America: leis e costumes. Trad. de Eduardo Brandão. São Paulo: Martins Fontes, 2005.

Data de submissão: 30/09/2020

Data de aprovação: 30/11/2020 